\title{
Padronização das informações toxicológicas no Brasil
}

\author{
Standardization of toxicological information in Brazil
}

Taís FreireGalvão ${ }^{1}$

M aurício GomesPereira ${ }^{1}$

${ }^{1}$ FaculdadedeM edicina, Universidade de Brasília. Campus Universitário Darcy Ribeiro, Faculdade de M edicina conj. 16 sala 77 , Asa N orte. 70910-900 Brasilia DF. taisgalvao@gmail.com
Senhor editor,

Interessante 0 artigo Sistema nacional de informações tóxico-farmacológicas: 0 desafio da padronização dos dados, publicado em número anterior desta revista [Cien Saude Colet 2011; 16(Supl. 1):1191-1200] ${ }^{1}$. Foi feito o relato de pesquisa realizada com os dados dos centros de informação eassistência toxicológica (CIAT) do País. 0 objetivo foi avaliar a padronização dos dados que estes centros voluntariamente enviam ao Sistema Nacional de Informações Tóxico-Farmacológicas (SINITOX). As autoras, de Santana RA, Bochner R e Guimarães M C, encaminharam casos hipotéticos para os centros e analisaram as respostas recebidas. Alguns aspectos do relato nos chamaram a atenção e os apresentamos a seguir para reflexão das autoras e dos leitores desta revista.

1) Não encontramos nenhuma menção à validação do instrumento utilizado. A exiguidade dos casos clínicos apresentados nos pare ceu não refletir a complexa realidade dos atendimentos. Na rotina, os casos são habitualmente acompanhados até a sua resolução, resultando em histórico bem mais completo do que o apresentado no questionário.

2) 0 padrão-ouro empregado para verificar a acurácia da classificação das substâncias, representado pelo conjunto de monografias de atendimento deurgências toxicológicas, somente permitiu classificação por um único ângulo. Isso dificultou o enquadramento correto de algumas substâncias. No caso 2, por exemplo, recomenda-seaplicar deltametrina no couro cabeludo por 10 minutos. As autoras concluíram que o correto seria classificar o produto como inseticida. Considerando que o uso corporal de inseticida não épermitido, a classificação como medicamento seria mais adequada, em acordo com a maioria das respostas recebidas.

3) As discordâncias das respostas foram avaliadas subjetivamente. 0 uso de um índice objetivo, como o Kappa, poderia revelar a concordância descontando o efeito do acaso.

4) Não localizamos informações sobre a data que ocorreu a investigação, de orientações eventualmente dispensadas aos entrevistados e de técnicas de pesquisa qualitativa utilizadas para avaliar as respostas das entrevistas. Uma melhor especificação do delineamento, por exemplo, enriqueceria o relato.

5) Parte-se do princípio de que os CIAT são fontes para notificação, aos quais cabe o registro dos dados. (1) Infelizmente, não há no Sistema Único de Saúde financiamento para os CIAT, o que os leva a depender exclusivamente da sensibilidade do gestor local (diretor do hospital, reitor da universidade, secretário desaúde) para manter o serviço em funcionamento. Este qua- 
dro resulta no fechamento de centros, incluindo 0 do Rio de Janeiro, a despeito dos mais de 25 anos de serviços prestados.

6) As respostas revelaram baixo grau de padronização. Este é o quadro esperado quando não há a uniformização da coleta dos dados. Quem deveria ser responsável pela padronização e falhou nesse processo? Essa e outras perguntas semel hantes poderiam compor a discussão dos resultados.

7) Fontes de informações padronizadas fornecem dados demelhor qualidade, a exemplo do Sistema de Informação sobre M ortalidade, citado no artigo, e de numerosos sistemas nacionais disponíveis². Esse processo de uniformização re quer recursos financeiros, pessoal e tempo para obter bons resultados. Atualmente prevê-se 0 preenchimento de tabelas e seu envio por fax ou correio eletrônico ao SI NITOX. Possivelmenteincorre em erros e dificuldades na análise. Soma-se a isso a baixa aderência dos CIAT a este sistema, observada nos últimos relatórios': 25 de 32 centros existentes em 2001 informavam seus dados ao SI N ITOX, totalizando cerca de 95 mil atendimentos. Em 2009, participaram apenas 21 de 37 centros, somando pouco mais de 82 mil casos. Portanto, houve aumento no número de centros, mas diminuição de centros notificantes e de casos registrados. Tais aspectos também mereceriam ser contemplados na discussão.

Para concluir, lembramos o exemplo do sistema de registro informatizado de intoxicações dos Estados Unidos, que regularmente divulga no meio científico e aos órgãos de governo os dados de exposição a substâncias ${ }^{4}$. Em 2009, foram reportados 4,3 milhões de atendimentos realizados pelos centros estadunidenses. A qualidade desses dados permite o direcionamento de ações preventivas e corretivas naquele país. 0 examedesistemas de registro com aparenteêxito poderia trazer subsídios para o aprimoramento das informações sobre intoxicações no Brasil.

\section{Referências}

1. Santana RA, Bochner R, Guimarães M C. Sistema nacional de informações tóxico-farmacológicas: 0 desafio da padronização dos dados. Cien Saude Colet 2011; 16(Supl. 1):1191-1200.

2. Rede Interagencial de Informação para a Saúde (RIPSA). Fontes de Informação. In: RIPSA. Indicadores Básicos da Saúde no Brasil: Conceitos e aplicações. 2ª ed. Brasília: OPAS; 2008. p. 315-327.

3. Bochner R. Sistema Nacional de Informações Tóxico-Farmacológicas. [página da internet]. [acessado 2011 maio 20]. Disponível em: http://www. fiocruz.br/sinitox

4. Bronstein AC, Spyker DA, Cantilena LR, Green JL, Rumack BH, Giffin SL. 2009 Annual Report of the American Association of Poison Control Centers' National Poison Data System (NPDS): $27^{\text {th }}$ Annual Report. Clin Toxicol (Phila) 2010; 48:979-1178. 